\title{
PENERAPAN PERILAKU HIDUP BERSIH DAN SEHAT (PHBS) DEMI KESEJAHTERAAN MASYARAKAT KECAMATAN TUNTANG KABUPATEN SEMARANG JAWA TENGAH
}

\author{
Fatwa Tentama dan mahasiswa KKN Reguler Divisi II.D \\ Universitas Ahmad Dahlan \\ E-mail: Fatwa.tentama@psy.uad.ac.id
}

\begin{abstract}
Abstrak
Perilaku Hidup Bersih dan Sehat (PHBS) merupakan suatu perilaku dimana seseorang menerapkan perilaku kebersihan dalam kehidupan sehari-harinya dengan memperhatikan tingkat kesehatannya. Hidup sehat merupakan hal yang seharusnya diterapkan oleh setiap orang karena manfaat yang didapat sangat banyak, mulai dari kesehatan jiwa dan raga hingga kefokusan dalam mengerjakan sesuatu, serta pada kesejahteraan hidup anggota keluarga serta terciptanya suasana yang indah, asri serta damai sehingga membuat lingkungan hidup terasa nyaman. Kelompok mahasiswa KKN UAD memiliki misi untuk menjadikan masyarakat kecamatan Tuntang Kabupaten Semarang menyadari akan pentingnya menerapkan Perilaku Hidup Bersih dan Sehat melalui beberapa program kerja terkait dengan PHBS. Beberapa kegiatan yang dilakukan yaitu JUMANTIK (Juru Pemantau jentik) serta penyuluhan cara memcuci tangan dengan tepat, yang dilakukan di beberapa desa di kawasan kecamatan Tuntang Kabupaten Semarang, mengingat masih rendahnya kesadaran masyarakat akan pentingnya kesehatan. Hasilnya, melalui beberapa kegiatan di atas mampu menyadarkan masyarakat akan pentingnya menerapkan Perilaku Hidup Bersih dan Sehat serta dapat memberi pengetahuan kepada masyarakat terkait bagaimana menerapkan perilaku hidup bersih dan sehat secara tepat.
\end{abstract}

Kata kunci: PHBS, Kecamatan Tuntang, Jumantik, cuci tangan.

\begin{abstract}
Clean and Healthy Living Behavior is a behavior in which a person applying hygiene behavior in their daily lives by paying attention to the level of health. Healthy living is something that should be applied by everyone due to its numerous benefits. The benefits of healthy living behavior are creating physical and mental health, focus in doing something, the welfare of family members and fine, beautiful and peaceful surroundings on thus making the environment feels comfortable. Students' groups of Community Service UAD have mission to make the people of Tuntang sub district of Semarang regency realize the importance of implementing Clean and Healthy Living Behavior through several programs related to it. Some of the activities carried out are JUMANTIK (Larvae Monitoring Team) and briefing on how to wash hands properly. These activities are done in some villages of sub district Tuntang Semarang regency due to the lack of public awareness to the importance of health. As a result, through some activities above, it causes people to be more aware to the importance of implementing Clean and Healthy Living Behavior and can provide knowledge to the public regarding on how to implement Clean and Healthy Living Behavior appropriately.
\end{abstract} hand.

Keywords: Clean and Healthy Living Behavior, Tuntang Sub District, Jumantik, washing 


\section{A. PENDAHULUAN}

Perilaku Hidup Bersih dan Sehat (PHBS) merupakan upaya untuk memberikan pengalaman belajar atau menciptakan suatu kondisi bagi perorangan, keluarga, kelompok dan masyarakat, dengan membuka jalan komunikasi, memberikan informasi, dan melakukan edukasi untuk meningkatkan pengetahuan serta sikap dan perilaku, melalui pendekatan pimpinan (advokasi), bina suasana (social support), serta pemberdayaan masyarakat (empowerman) sebagai suatu upaya untuk membantu masyarakat untuk mengenali dan mengatasi masalahnya sendiri, dalam tatanan masing-masing agar dapat menerapkan cara-cara hidup sehat dalam rangka menjaga, memelihara, dan meningkatkan kesehatan (Maryunani, 2013). Menerapkan perilaku hidup sehat sebenarnya sangatlah mudah serta murah, dibandingkan harus mengeluarkan biaya untuk pengobatan apabila mengalami gangguan kesehatan. Hidup sehat merupakan hal yang seharusnya diterapkan oleh setiap orang karena manfaat yang didapat sangat banyak, mulai dari kefokusan dalam mengerjakan sesuatu, hingga pada kesejahteraan hidup anggota keluaga.

Perilaku Hidup Bersih dan Sehat (PHBS) juga merupakan semua perilaku kesehatan yang dilakukan atas kesadaran seseorang sehingga dapat menangani dirinya sendiri dalam hal kesehatan serta dapat berperan aktif dalam kegiatan-kegiatan kesehatan baik bagi individu masing-masing atau pada orang lain. Sayangnya belum semua orang memahami tentang apa arti hidup sehat itu, hal ini dibuktikan dengan masih banyaknya masyarakat yang melakukan berbagai aktivitas tanpa memperdulikan tingkat kesehatannya, salah satu contoh yaitu ketika seorang anak selesai melakukan suatu pekerjaan di luar rumah, orang tua tidak membiasakan anak untuk mencuci tangan dan kakinya ketika masuk rumah dan anak dibiarkan melakukan kegiatan yang baru begitu saja, contoh lain yaitu ketika kebersihan kamar mandi kurang diperhatikan dan dibiarkan begitu saja terlebih pada kebersihan bak mandi. Perilaku-perilaku tersebut memang terlihat sepele namun berdampak besar ketika menjadi kebiasaan. Untuk itu diperlukan pemberitahuan atau informasi terkait pengetahuan tentang Perilaku Hidup Bersih dan Sehat (PHBS) kepada masyarakat, supaya tumbuh kesadaran akan pentingnya menerapkan PHBS pada masyarakat demi kesehatan dan kesejahteraan anggota keluarga.

Dalam rangka mengoperasionalkan paradigma sehat khususnya yang berkaitan dengan promosi kesehatan di Indonesia, Menteri Kesehatan Republik Indonesia membuat Pedoman Pembinaan Perilaku Hidup Bersih dan Sehat yang tertuang dalam Peraturan Menteri Kesehatan Republik Indonesia Nomor: 2269/MENKES/PER/XI/2011 yang mengatur upaya peningkatan Perilaku Hidup Bersih dan Sehat(PHBS) di seluruh Indonesia dengan mengacu kepada pola manajemen PHBS, mulai dari tahap pengkajian, perencanaan, dan pelaksanaan serta pemantauan dan penilaian. Upaya tersebut dilakukan untuk memberdayakan masyarakat dalam memelihara, meningkatkan dan melindungi kesehatannya sehingga masyarakat sadar, mau, dan mampu secara mandiri turut berperan aktif dalam meningkatkan status kesehatannya. Meskipun upaya tersebut bukanlah suatu hal yang mudah karena berkaitan dengan masalah perilaku, sedangkan perilaku merupakan masalah yang khas dan kompleks karena berkaitan dengan privasi seorang individu, untuk itu harus dilakukan pendekatan kepada masyarakat terlebih dulu guna memberikan kepercayaan dan menginformasikan manfaat-manfaat yang akan didapatkan ketika 
menerapkan PHBS tersebut, mengingat pemberdayaan masyarakat sebaiknya dimulai dari rumah tangga atau keluarga, karena berawal dari keluarga yang sehat timbullah generasigenerasi masa depan yang cemerlang.

Berdasarkan hasil observasi yang dilakukan oleh mahasiswa KKN Reguler Universitas Ahmad Dahlan periode 61 yang berlokasi di Kecamatan Tuntang Kabupaten Semarang, masih banyak masyarakat yang belum menyadari pentingnya perilaku hidup bersih dan sehat. Oleh karena itu, mahasiswa KKN UAD memiliki misi untuk menjadikan masyarakat kecamatan Tuntang Kabupaten Semarang menyadari akan pentingnya menerapkan Perilaku Hidup Bersih dan Sehat dengan melakukan beberapa program kerja terkait dengan PHBS. Beberapa kegiatan yang dilakukan, yaitu JUMANTIK (juru pemantau jentik) dan penyuluhan cara memcuci tangan dengan tepat, yang dilakukan di beberapa desa di kawasan kecamatan Tuntang Kabupaten Semarang.

\section{B. METODE PELAKSANAAN}

Metode pelaksanaan yang dilakukan oleh mahasiswa Kuliah Kerja Nyata Universitas Ahmad Dahlan adalah dengan memberikah penyuluhan dengan menjelaskan hal-hal yang terkait dengan cara menerapkan Perilaku Hidup Bersih dan Sehat (PHBS) yang sedang dilaksanakan serta memberikan contoh dengan mempraktekannya di depan para masyarakat. Hal ini dilakukan supaya masyarakat tidak hanya mengetahui cara melakukannya saja tetapi masyarakat juga mengetahui manfaat dengan menerapkannya di kehidupan sehari-hari kegiatan tersebut serta mengetahui bahayanya jika tidak menerapkannya.

Beberapa kegiatan terkait Perilaku Hidup Bersih dan Sehat yang terlaksana yaitu Jumantik (Juru Pemantau Jentik), kegiatan Jumantik merupakan suatu bentuk progam pemeliharaan kesehatan yang dilakukan dengan cara pengecekan jentik-jentik nyamuk pada tampungan air yang terdapat di lingkungan rumah warga. Selain pengecekan jentik, progam Jumantik juga memberikan wawasan tentang siklus hidup nyamuk, tempat berkembangbiaknya nyamuk, penyakit-penyakit yang disebabkan oleh nyamuk, dan cara penanggulanganya. Kegiatan Jumantik dilaksanakan di desa Tuntang dan dilakukan di dua dusun yaitu Dusun Gading dan Dusun Cikal dengan menyiapkan form khusus yang digunakan untuk mendata keberadaan jentik pada tiap- tiap rumah warga, pemeriksaan difokuskan pada penampungan air (bakmandi, gentong, vas bunga, kolam, kalengkalengbekas, serta tempayan). Dari hasil pemantauan jentik, didapatkan data primer yang menujukan tingginya populasi jentik di DesaTuntang terutama di Dusun Cikal. Dusun Cikal yang secara geografis berada tepat di pinggiran Rawa Pening memiliki potensi yang paling tinggi dibanding dengan lainya. Dibutuhkan penanganan dan perhatian yang lebih intensif. Progam Jumantik yang telah dilakukan oleh tim KKN UAD telah sukses membuka matahati dari para penduduk Desa Tuntang untuk peduli terhadap lingkungan di sekitarnya. Berawal dari juru pemantau jentik yang berkeliling di rumah warga untuk memeriksa keberadaan jentik, lambat laun masyarakat yang berkordinasi dengan Kadus mulai rutin melakukan gotongroyong untuk memelihara kebersihan lingkungan, diantaranya mengubur sampah-sampah yang dapat digenangi air. 
Selain kegiatan Jumantik, kegiatan lain yang dilakukan oleh kelompok mahasiswa KKN UAD yaitu memberikan penyuluhan tentang cara mencuci tangan dengan tepat. Mencuci tangan merupakan kegiatan yang wajib dilakukan ketika sebelum dan sesudah makan, tujuannya yaitu untuk menghilangkan kuman-kuman dan bakteri yang menempel pada tangan, sela-sela jari, serta pada kuku, karena tangan merupakan salah satu agen utama masuknya kuman/mikroba penyebab penyakit kemulut, hidung dan anggota tubuh lainnya, bisa melalui makanan dan minuman atau benda-benda yang menempel ditangan kita baik secara sengaja atau tidak sengaja, selain untuk diri sendiri tangan juga sebagai sumber penyaluran kuman dari satu orang ke orang lainnya, untuk itu, mengapa aktivitas mencuci tangan harus selalu dilakukan. Mencuci tangan tidak cukup hanya membilas kedua telapak tangan dengan air bersih saja, namun diperlukan adanya sabun serta cara mencuci tangan yang tepat supaya tangan benar-benar bersih dari kuman sehingga penyakit tidak mudah masuk ke dalam tubuh kita, pada kegiatan ini kelompok mahasiswa KKN UAD memberikan penyuluhan serta cara bagaimana mencuci tangan dengan tepat kepada siswasiswa Taman Kanak-Kanak di desa Lopait, hal ini dilakukan dengan tujuan menanamkan pengetahuan sejak dini pada anak-anak untuk selalu mencuci tangan sebelum dan sesudah makan serta mengajarkan mereka untuk dapat melakukannya sendiri tanpa harus bergantung pada orang lain. Hasilnya anak-anak menjadi mampu melakukannya sendiri tanpa harus dibantu orang lain, dan mereka menjadi membiasakan diri untuk mencuci tangannya sebelum dan sesudah makan tanpa harus disuruh lagi, karena mereka sudah tahu apa manfaat serta akibat bila tidak membiasakan diri dengan mencuci tangan. Metode, kegiatan, JKEM dan keterlibatan mahasiswa tersaji pada table I.

Tabel I. Metode, Kegiatan, JKEM, dan keterlibatan mahasiswa

\begin{tabular}{|l|l|c|l|}
\hline \multicolumn{1}{|c|}{ Metode } & \multicolumn{1}{|c|}{ Kegiatan } & JKEM & \multicolumn{1}{c|}{$\begin{array}{c}\text { Jumlah } \\
\text { mahasiswa } \\
\text { yang terlibat }\end{array}$} \\
\hline Pendidikan \\
$\begin{array}{l}\text { masyarakat dan } \\
\text { Praktek }\end{array}$ & $\begin{array}{l}\text { Melaksanakan JUMANTIK } \\
\text { (Juru Pemantau Jentik) }\end{array}$ & $4 \times 250$ Menit & 27 \\
\cline { 2 - 4 } & $\begin{array}{l}\text { Mengadakan penyuluhan } \\
\text { tentang cara mencuci tangan } \\
\text { yang baik }\end{array}$ & $4 \times 200$ menit & 27 \\
\hline
\end{tabular}

\section{HASIL, PEMBAHASAN, DAN DAMPAK}

Jumantik atau biasa disebut juru pemantau jentik merupakan kegiatan pengecekan jentik nyamuk ke rumah-rumah warga secara langsung, jumantik berperan untuk meningkatkan kewaspadaan dan kesiapan masyarakat menghadapi demam berdarah dengue (DBD), selain DBD, penyakit yang dapat disebabkan oleh nyamuk adalah malaria, kaki gajah, serta flu tulang (cikungunya). Sasaran dari kegiatan JUMANTIK ini yaitu para warga di desa Tuntang kecamatan Tuntang Kabupaten Semarang. Kegiatan ini dilakukan bekerja sama dengan para pemuda dan pemudi demi mempermudah akses perizinan pada warga. Pada kegiatan ini pemantu yang terdiri dari mahasiswa beserta pemuda-pemudi desa Tuntang menyiapkan form khusus yang digunakan untuk mendata keberadaan jentik pada 
tiap- tiap rumah warga, pemeriksaan yang difokuskan pada penampungan air (bak mandi, gentong, vas bunga, kolam, kaleng- kaleng bekas, tempayan), dan jumlah jentik yang ada. Pemantau jentik juga memberikan beberapa pertanyaan terhadap warga tentang frekuensi dalam menguras bak mandi, dan tampungan air lainya, untuk rumah yang terdapat banyak jentik- jentik nyamuk maka para petugas menyarankan untuk melakukan pengurasan bak mandi kurang lebih satu minggu sekali dan jika keberadaan jentik masih tidak dapat ditanggulangi maka dianjurkan untuk menggunakan obat abate yang bisa diperoleh di puskesmas atau apotek.

Selanjutnya yaitu kegiatan penyuluhan cara mencuci tangan dengan tepat, kegiatan ini dilaksanakan di beberapa sekolah taman kanak-kanak di desa Lopait dengan sasaran yaitu seluruh siswa taman kanak-kanak. Kegiatan ini dilakukan dengan tujuan mengedukasi siswa dalam hal menjaga kebersihan sejak dini, serta memberi contoh bagaimana cara mencuci tangan dengan baik dan benar, supaya nantinya mereka faham bagaimana caranya mencuci tangan sendiri dengan benar tanpa perlu bantuan orang lain, secara tidak langsung kegiatan ini juga mengasah kemandirian siswa dalam melakukan aktivitasnya sendiri. Sebelum diberi contoh, anak-anak terlebih dulu diasah pengetahuannya tentang cara yang biasa mereka lakukan dalam mencuci tangan, kemudian apa saja yang mereka ketahui tentang manfaat mencuci tangan sebelum makan serta akibat bila tidak mencuci tangan terlebih dahulu. Setelah itu pemateri mengoreksi tentang apa yang sudah disebutkan oleh anak-anak tadi, dan meluruskan pemahaman anak tentang arti kebersihan melalui kegiatan mencuci tangan. Kemudian, anak-anak diajak untuk memperhatikan cara mencuci tangan yang tepat dengan menggunakan sabun serta air bersih, dan terakhir anak-anak diminta untuk mempraktekannya secara bergantian ke depan kelas sekaligus mengambil makanan untuk dimakan bersama.

Melalui beberapa kegiatan yang dilakukan oleh kelompok mahasiswa KKN UAD ini mampu menyadarkan masyarakat dalam menerapkan Perilaku Hidup Bersih dan Sehat, hal ini dibuktikan dengan pengakuan dari beberapa masyarakat bahwa sebelum diadakannya penyuluhan terkait penerapan Perilaku Hidup Bersih dan Sehat ini mereka sama sekali tidak mengerti bagaimana cara melakukannya dengan baik dan benar, namun setelah dilakukannya kegiatan tersebut masyarakat menjadi lebih paham serta mengerti bagaimana cara melakukannya dengan tepat dan sepakat untuk selalu menerapkannya dalam kehidupannya sehari-hari. Sebagian besar masyarakat berharap kegiatan ini rutin dilaksanakan dan lebih banyak lagi pembahasan mengenai cara menerapkan perilaku hidup bersih dan sehat oleh pihak-pihak yang berwenang, terlebih pada pemeriksaan jentik nyamuk di rumah-rumah warga.

Gambar aktivitas mahasiswa KKN UAD dan masyarakat dalam program penerapan perilaku hidup bersih dan sehat (PHBS) tersaji pada gambar 1. 


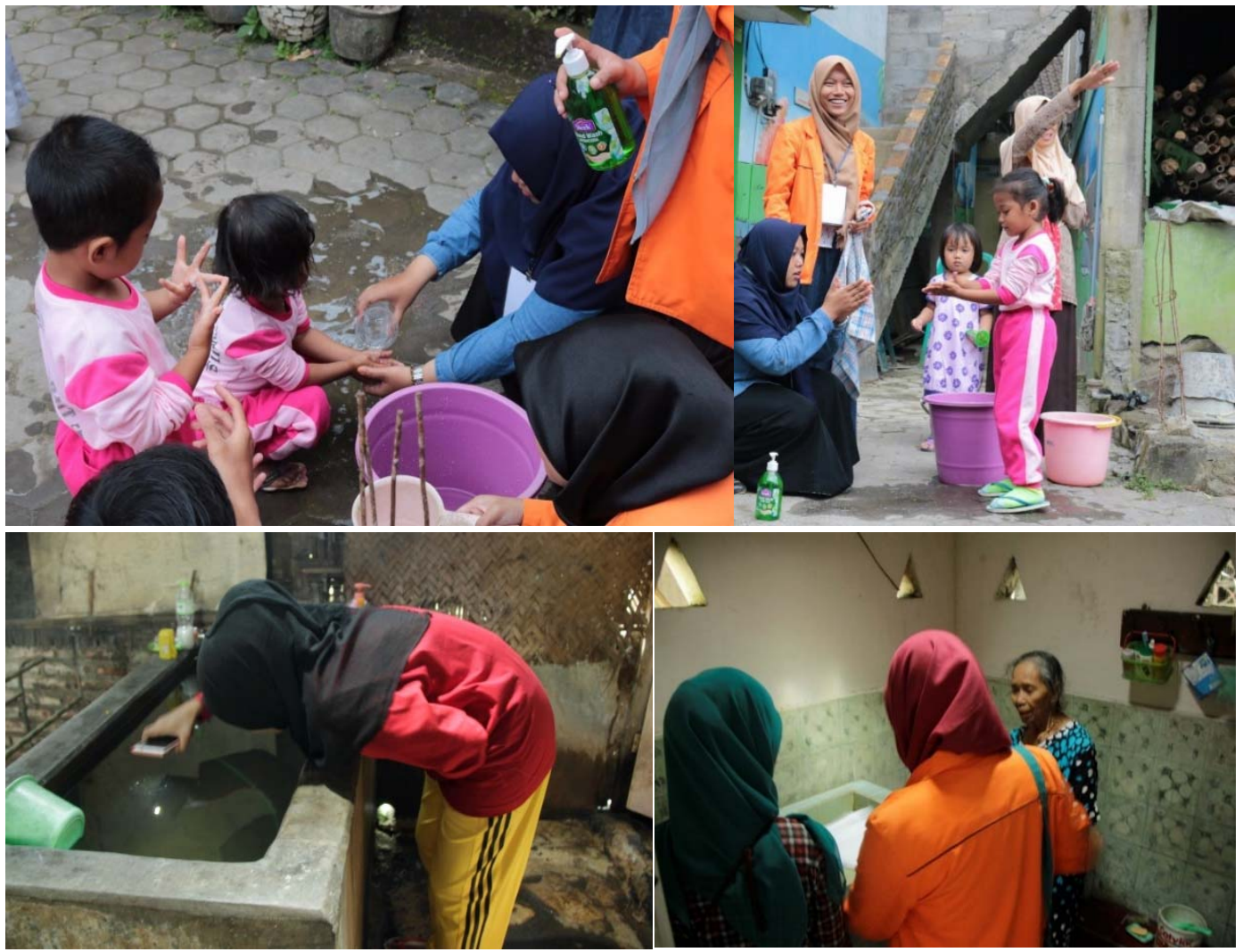

Gambar 1. Aktivitas mahasiswa KKN UAD dan masyarakat Kecamatan Tuntang dalam program Perilaku Hidup Bersih dan Sehat (PHBS)

\section{KESIMPULAN}

Melaui kegiatan yang diadakan oleh kelompok mahasiswa KKN UAD dapat ditarik kesimpulan bahwa sebuah pengetahuan tidak akan dapat difahami secara menyeluruh bila tidak disertai dengan contoh, untuk itu dalam hal penerapan perilaku hidup bersih dan sehat orang tua diharapkan dapat memberi contoh kepada anak-anaknya supaya tertanam pula dalam diri mereka bahwa menerapkan perilaku hidup bersih dan sehat itu penting, baik bagi dirinya sendiri ataupun bagi orang lain serta lingkungan di sekitarnya, supaya tercipta suasana yang indah, asri, damai, serta sehat sehingga akan berdampak pada kesejahteraan kehidupan masyarakat di Kecamatan Tuntang, Kabupaten Semarang.

\section{DAFTAR PUSTAKA}

Maryunani Anik, Perilaku Hidup bersih dan Sehat (PHBS) untuk mahasiswa kesehatan dan petugas kesehatan, Trans Info Media : Jakarta, 2013

Proverawati Atikah, Perilaku Hidup Bersih dan Sehat, Nuha Medika: Yogyakarta, 2012 